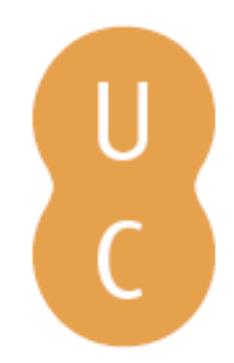

\title{
pompalina
}

Cidade, água, património: as razões de um projeto

Autor(es): $\quad$ Farinella, Romeo

Publicado por: Imprensa da Universidade de Coimbra

URL

persistente: URI:http://hdl.handle.net/10316.2/39316

DOI: $\quad$ DOI:http://dx.doi.org/10.14195/978-989-26-1025-2_1

Accessed : $\quad$ 26-Apr-2023 05:00:39

A navegação consulta e descarregamento dos títulos inseridos nas Bibliotecas Digitais UC Digitalis, UC Pombalina e UC Impactum, pressupõem a aceitação plena e sem reservas dos Termos e Condições de Uso destas Bibliotecas Digitais, disponíveis em https://digitalis.uc.pt/pt-pt/termos.

Conforme exposto nos referidos Termos e Condições de Uso, o descarregamento de títulos de acesso restrito requer uma licença válida de autorização devendo o utilizador aceder ao(s) documento(s) a partir de um endereço de IP da instituição detentora da supramencionada licença.

Ao utilizador é apenas permitido o descarregamento para uso pessoal, pelo que o emprego do(s) título(s) descarregado(s) para outro fim, designadamente comercial, carece de autorização do respetivo autor ou editor da obra.

Na medida em que todas as obras da UC Digitalis se encontram protegidas pelo Código do Direito de Autor e Direitos Conexos e demais legislação aplicável, toda a cópia, parcial ou total, deste documento, nos casos em que é legalmente admitida, deverá conter ou fazer-se acompanhar por este aviso.

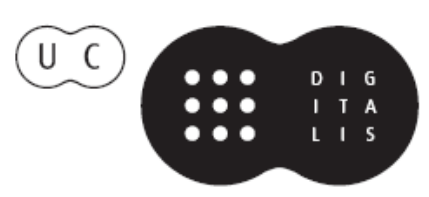




\section{CIDADE, ÁGUA, PATRIMÓNIO AS RAZÕES DE UM PROJETO}

ROMEO FARINELLA 


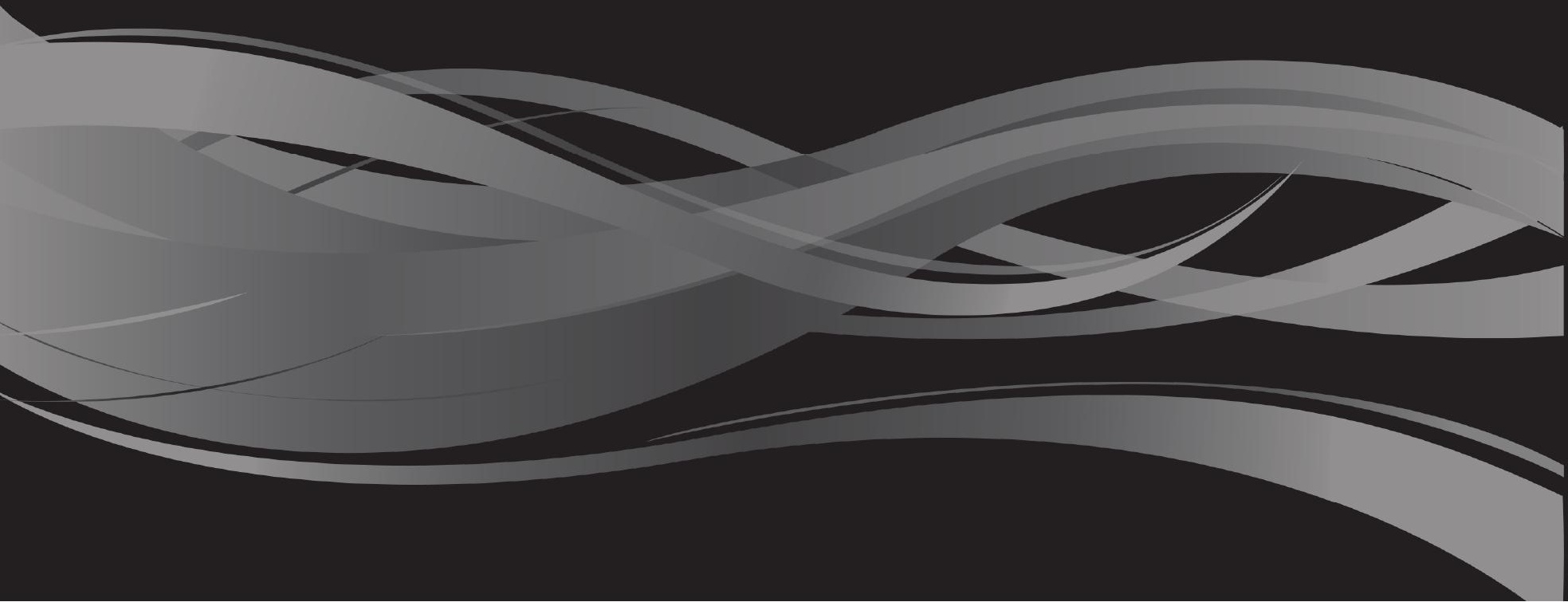




\section{ÁGUA COMO PATRIMÓNIO: A PROBLEMÁTICA}

Em dezembro de 1969, André Chastel fechava um editorial no quotidiano Le Monde, dedicado ao tema da requalificação da zona parisiense de Halles, exprimindo a sua perplexidade sobre a anunciada e, de seguida, concretizada destruição do antigo mercado. O historiador relembrava a atmosfera plena de história e cultura presente naquele espaço fascinante, intimamente ligada às estradas, às fachadas e ao ambiente do contexto urbano circundante, construído ao longo dos séculos. Devido a esta sedimentação, afirmava Chastel (2012), muitas vezes, o aspeto limpo e um pouco infantil das modernas requalificações parece um produto de laboratório, desapegado da história. A história, continua o historiador, é um aspeto do problema a controlar e que obriga a um pouco de complexidade.

Esta complexidade é, sem dúvida, um aspeto forte da sua reflexão, por vários motivos. Enunciemos alguns. Toda a modernização da cidade proposta pelas grandes teorias urbanísticas do fim do século XIX e, muitas vezes, executada contra os preceitos dos pais fundadores da urbanística, baseia-se num princípio de simplificação ditado por exigências higiénicas, de circulação, de reorganização funcional dos espaços de vida e trabalho, necessárias para acabar com a promiscuidade que sempre tinha caracterizado o crescimento da cidade pós-industrial. A cidade tende a tornar-se uma máquina onde cada componente desenvolve a sua tarefa, mas no seu respetivo espaço.

Na realidade, a racionalização dos nossos espaços urbanos respondeu a exigências de simplificação ditadas pelos impulsos do mercado imobiliário e das especulações que construíram a cidade contemporânea. Hoje, a complexidade está na base do pensamento sustentável.

Quando Chastel chamou a atenção para a complexidade da história como "material" do projeto urbano, como diríamos hoje, em França estava a chegar ao fim o período denominado Trentes Gloriueses.

É o período que os italianos conhecem como "Boom económico". Entre 1945 e 1973, o modelo de desenvolvimento baseou-se exclusivamente na ilusão do crescimento económico ilimitado.

A metrópole crescia a olhos vistos e o Presidente da Câmara Delauvrier tinha por objetivo dar formas e dimensões de cidade à enorme banlieue parisiense. São várias as histórias a este propósito que marcaram a transformação das nossas cidades ao longo do século XX.

Uma década antes, em 1957, numa conferência do Instituto Italiano de Urbanística dedicado à defesa e valorização da paisagem urbana e rural' , Adriano Olivetti declarava o seguinte:

“...podemos afirmar de firme consciência que o problema da conservação do património artístico e natural não é tanto um problema técnico e crítico, mas sim um problema político e moral. Uma sociedade que aspire verdadeiramente a ser mais elevada e melhor deve abordar a questão pelo todo".

1 Trata-se da Conferência da INU “Defesa e valorização da paisagem urbana e rural, ocorrida em Lucca, em 1957. 
Esta afirmação exprime de forma sintética a complexidade do tema da conservação dos centros históricos e da paisagem na experiência urbanística italiana da segunda metade do século XX. A importância da história emerge nas visões de Chastel e de Olivetti como portadora de uma ideia mais avançada de sociedade que considera o seu património como ponto de partida para um projeto de futuro.

O conceito de património é uma noção recente, moderna, como referiu Françoise Choay (1993). Através da retórica dos monumentos, ao longo do século XIX e início do século XX, forjaram-se as identidades nacionais europeias. A cultura iluminista e a Revolução Francesa lançaram a ideia da conservação do património como objeto das políticas nacionais. O século XIX foi o século em que se puseram em prática ações que levaram à consolidação das legislações nacionais. Em 1837, instituiu-se a Commission des Monuments Historiques graças à ação de Prosper Mérimée. Esta comissão fez trabaIhos de inventariação e de classificação e encarregou-se de formar os arquitetos que iriam intervir na conservação dos monumentos. Quarenta anos depois, em Inglaterra, William Morris fundou a Society for the Protection of Ancient Buildings. No início do século XX, emergiu também o tema da natureza como objeto de tutela. Nos Estados Unidos, Theodore Roosevelt lançou uma campanha para a salvaguarda da natureza como caráter identitário da nova nação e como obrigação moral para as gerações futuras (Settis, 2010). O processo, já iniciado sob a presidência de Lincoln, com a instituição do parque de Yosemite, na Califórnia, completou-se com a formação, em 1916, da agência federal encarregue da gestão do National System Park. Em Itália, as diversas normas introduzidas pelos antigos estados nas sucessivas ações de legislação preocuparam-se mais com questões de tutela e património do que com a unidade do país. Durante o vinténio fascista, a promulgação da nossa atual Constituição republicana marcou a evolução das políticas de tutela no nosso país (idem).

Hoje, além das legislações nacionais que determinam a ação dos vários países, existem alguns fatores que tornam mais complexo o quadro operativo. Trata-se da função das organizações internacionais que interagem, mais ou menos diretamente, com as políticas nacionais urbanas, territoriais e de tutela do património. Por exemplo, os acordos de redução de emissões de gases com efeito de estufa para a atmosfera, iniciados em 1997, em Kyoto, colocam à comunidade internacional o problema de qual o modelo de desenvolvimento a seguir; as consequências dos gases nas cidades interessam para a relação entre a conservação dos edifícios históricos e a sua preparação do ponto de vista do consumo energético. Por sua vez, a paisagem urbana poderia ser reinventada em caso de concretização das hipóteses de reflorestação urbana elaboradas para a reorganização de muitas áreas urbanas e metropolitanas europeias.

Em 2007, a União Europeia promulgou a Carta de Lipsia para as cidades sustentáveis, incentivando os estados membros a iniciarem um debate político para compreender como integrar as estratégias, com base na Carta, nas políticas de desenvolvimento nacional, regional e local. No centro da reflexão e das futuras ações está a necessidade de alcançar um desenvolvimento urbano integrado, de modo a promover uma organização territorial equilibrada e policêntrica. As cidades devem ser repensadas como organismos compactos com uma estreita ligação às zonas naturais e rurais preservadas, revalorizadas ou projetadas. Esta ideia baseia-se no conceito de qualidade urbana entendida como síntese da qualidade ambiental, social e económica e dos espaços públicos. 
O tema da paisagem como base para as políticas urbanas e territoriais foi sancionado em 2000 pela Convenção Europeia da Paisagem. Trata-se de uma iniciativa do Conselho da Europa que é um organismo mais amplo em relação à União Europeia e incluiu países que não pertencem à União Europeia. A convenção apresentada em Florença foi depois assinada e ratificada apenas por 35 países e entre estes não fazem parte a Alemanha e a Áustria. De que se trata? Certamente que não é uma norma que comporta uma adaptação automática às legislações nacionais dos países que a subscreveram. É um documento que promove e estimula a atenção à paisagem como fator estrutural das políticas urbanas e territoriais. Não obstante as definições genéricas introduzidas, pode constituir, em particular para os países que têm menos prática com as políticas de tutela paisagística, uma importante base de partida para uma reflexão sobre os seguintes aspetos: a tutela do património paisagístico; a qualidade dos processos de transformação urbana e territorial (que construirão as paisagens de amanhã); a qualidade paisagística nas estratégias, nos objetivos e nas ações de governação do território.

No aspeto patrimonial, recorde-se o debate em curso na UNESCO sobre a tutela dos "patrimónios urbanos históricos" (Bandarim e van Oers, 2012). Esta reflexão representa uma evolução das definições, dos princípios e das linhas orientadoras para o restauro e conservação dos bens patrimoniais que, desde 1931, marcaram a redação de numerosas "cartas": de Atenas a Veneza, de Amesterdão a Cracóvia. O tema da cidade e dos centros históricos constitui um dos aspetos mais importantes desta elaboração, que em Itália foi enriquecida também pelas reflexões da Associação nacional de centros histórico-artísticos (ANCSA) e sintetizadas nas cartas de Gubbio de 1960 e de 1990, com importantes consequências na cooperação internacional e, em particular, na América Latina (Toppetti, 2011). A "paisagem urbana histórica" nas recomendações da Unesco, apresentadas em 2011, é entendida como o resultado de uma estratificação histórica de valores, fatores culturais e naturais que ultrapassam a noção consolidada de "centro histórico" que marcou durante anos, em Itália, uma das categorias operativas da nossa prática urbanística. A definição refere-se a um contexto urbano e geográfico mais amplo, fruto de processos seculares de estratificação e de sedimentação histórica que lhe deram uma forma. Trata-se de um conceito que, segundo os especialistas que se confrontaram com esta nova locução, não substitui as práticas locais e nacionais consolidadas, mas integra-as propondo uma categoria operativa a utilizar na definição das políticas de tutela e planificação urbana e territorial. Através desta definição conceptual, a "Recomendação" pretende contribuir para a renovação dos instrumentos jurídicos, técnicos e de planificação necessários para reconhecer, catalogar e conservar os valores associáveis ao conceito de "paisagem urbana histórica". A evolução dos documentos que em Itália e a nível internacional estão a reorientar as políticas de conservação do património, cada vez mais associa a dimensão da conservação à da inovação. A conservação torna-se, neste sentido, um momento fundamental do processo de regeneração das nossas cidades. Por outras palavras, coloca-se de novo o problema da história como ponto de partida para o projeto contemporâneo que não é mais do que o percurso seguido no desenvolvimento das atividades de projeto apresentadas neste volume. História e local podem representar duas dimensões operativas de uma estratégia de desenvolvimento, nomeadamente "local", mas necessária para competir num mundo cada vez mais globalizado (Magnaghi, 2010). 
"Água como património" é um título simultaneamente evocativo e pró-ativo. Por um lado, recorda a história das cidades e as relações com a água que se estabeleceram ao longo dos séculos. Por outro interroga as formas presentes e futuras destas relações. Historicamente, a água foi um recurso para a cidade, uma fonte de energia, uma infra-estrutura de mobilidade e recetor de resíduos. Entre o século XVII e o século XVIII, os troços urbanos de muitos rios começaram a ser transformados em locais monumentais. Com a Revolução Industrial, o curso de água tornou-se uma fonte energética e infra-estrutura portuária para o transporte de mercadorias, mas transformou-se também num local de degradação e de poluição. Com a crise do modelo industrial, nos anos 1970 e 1980 do século XX, muitos espaços fluviais tornaram-se cemitérios de áreas produtivas ou infra-estruturais abandonadas, mas de seguida originaram oportunidades de requalificação. Hoje, são muitas vezes evocados como locais de redescoberta de espaços abandonados das cidades a regenerar e a transformar em espaços públicos, novas polaridades urbanas ou corredores ecológicos.

Como num palimpsesto, ao longo do tempo estes processos reescreveram a estrutura de muitos territórios e deixaram numerosos rastos. As velhas ordens territoriais foram substituídas por novas. Em alguns casos, reaproveitaram-se (ou fundaram-se) velhas estruturas ou urdiduras do solo e este processo de "estranhamento" muitas vezes descontextualizou aquilo que restava dos históricos sistemas de instalação do território. Podemos mencionar, a este propósito, a permanência de traços da centurização romana nos territórios da planície do Pó, com vista a uma urbanização difusa, ou os traços de antigas urdiduras rurais como os murs à pêche (viveiros) nas periferias da região parisiense.

Trata-se de um processo que, ao longo do tempo, modificou, alterou e apagou formas urbanas, mas que nos permite hoje redescobrir e identificar rastos, estruturas e elementos, frequentemente minimais, que são testemunhos da riqueza de relações estabelecidas entre a água e as cidades. A introdução do termo "património" neste contexto pode ser surpreendente. Porquê? Certamente devido à dimensão conservativa que o identifica. A evolução das problemáticas de salvaguarda dos bens culturais em toda a Europa foi bem entendida, ainda que diferenciada. De uma ideia de "monumento" passou-se rapidamente ao conceito de cidade e de tecido urbano menor, que reencontramos por exemplo na problemática dos "centros históricos" e, hoje, no referido conceito de "paisagem urbana histórica". O conceito de bem paisagístico, por sua vez, foi alargado para o de "paisagem cultural", que permitiu aumentar a área da tutela e da sensibilidade a âmbitos mais vastos. Na verdade, o conceito de "paisagem cultural" pode ser motivo de confusão, uma vez que a paisagem é por definição cultural, independentemente de ser bela ou desagradável. Quando o homem começou a usar a charrua, o solo passou de terra a território. De seguida, foi necessária a evolução de alguns séculos de cultura literária, pictórica e estética, chinesa e europeia, de modo a que fosse reconhecida uma dimensão estética a este processo de construção do território, transformando-o assim em paisagem (Berque, 1995). Por fim, há algumas décadas atrás atribuiu-se um valor patrimonial também aos locais de trabalho e começou-se a falar em paisagens do trabalho e arqueologia industrial. Mas, como vimos, o conceito de "património" pode ser também o ponto de partida para um projeto contemporâneo das cidades e dos territórios. Há alguns anos atrás, um eficaz slogan do Ministério da Cultura francês 
procurava afastar a desconfiança dos franceses em relação à arquitetura contemporânea, lançando a mensagem de que a arquitetura de hoje será o património de amanhã. Uma provocação eficaz que atribui a cada um de nós (intelectuais, administradores, técnicos, citadinos) responsabilidades e que carrega de significado e responsabilidade as nossas ações de transformação do território. No desenvolvimento das problemáticas e das normas (códigos, leis, regulamentos) que na Europa colocaram o problema de governar as transformações territoriais, tutelando os valores patrimoniais, paisagísticos e monumentais, cruzaram-se sempre determinados aspetos e pontos de vista:

-a relação entre inovação e conservação;

-a relação entre natureza e cultura;

-o equilíbrio entre o interesse público e privado;

-a relação entre o universal e o identitário.

No que respeita ao primeiro aspeto, a questão está em aferir se a inovação (e, portanto, o projeto contemporâneo) e a conservação (e, portanto, a tutela dos valores e lugares do passado) representam duas dimensões que convivem lado a lado sem interagir ou se, pelo contrário, podem coexistir integradas numa mesma ideia ou estratégia. Em 1990, a atualização da Carta de Gubbio colocou o tema da conservação como questão estrutural e "privilegiada" do projeto. O tema das permanências e da memória torna-se em ação de projeto, um ato criativo que contribui para o processo de transformação urbana. Para trás fica a "tábua rasa" que encontramos na Carta de Atenas, a qual nos tinha habituado a uma retórica do Movimento Moderno. O tema da enxertia do ato arquitectónico inovador num contexto ou num local formado ao longo de um processo secular de estratificação é uma reflexão que muitos autores propuseram (Choay, 2011; Gambino, 1997). Trata-se de uma relação dialéctica que não pode medir-se com a ideia de que cada território é o resultado de um processo de estratificação histórica que pode ser reescrito, como referimos a propósito do palimpsesto. É necessário conhecer bem as regras e sintaxes.

A relação entre natureza e cultura não é certamente um tema novo para quem se ocupa de cidades e de território. Hoje, em toda a Europa, há uma grande discussão sobre como restabelecer as relações entre a cidade e a natureza para se atingir o objetivo de ter uma cidade sustentável. Trata-se, na realidade, de um tema que levou ao nascimento da urbanística como disciplina necessária para sanar os males da cidade industrial. Como recorda Pierre Lavedan, a urbanística nasceu para estudar as terapias para uma cidade adoentada devido à revolução industrial. A higiene urbana representava o antídoto para curar o corpo urbano doente e, entre as medidas previstas, a introdução de zonas verdes na cidade não foi por certo secundária. Na passagem do século XIX para o XX, apareceram algumas ideias importantes de reconfiguração metropolitana através da natureza. A primeira pode ser atribuída a Frederick Law Olmsted, um dos pais da planificação paisagística que experimentou nos seus projetos o conceito de Park System, ou seja, a utilização de componentes naturais e geográficos presentes no interior e em redor da cidade, para construir uma rede interligada de espaços naturais. Em Boston, a Emerald Necklace atravessa 5 milhas da área metropolitana e esta ideia foi seguida pelo paisagista 
Jean Claude Nicolas Forestler e proposta para a reorganização da região parisiense. Mas podemos falar também dos espaços naturais utilizados como coroa, cintura e cunha em numerosas propostas de organização urbana, experimentadas nas cidades ocidentais: de Berlim a Copenhaga, de Amesterdão a Helsínquia. O verde na cidade, na aceção dupla de natureza urbana e de espaço público, é, portanto, uma aquisição recente, mas hoje a cidade já não é um organismo compacto. Ao longo do século XX, o "desejo" de urbanização, depois de ter transformado os terrenos externos mas contíguos à cidade, foi mais além e investiu-se em territórios rurais entre as cidades e as metrópoles. Estas regiões urbanizadas, que os urbanistas começaram a denominar e a descrever como uma "cidade difusa" (Indovina et al., 1990), apareceram compostas por urbanizações incoerentes. Aqui estão presentes centros históricos, periferias residenciais consolidadas, novas áreas residenciais com lotes unifamiliares, áreas artesanais e produtivas, infra-estruturas rodoviárias e zonas de campo já fragmentadas e muitas vezes urbanizadas.

A sua configuração vasta pôs em causa as habituais divisões administrativas e coloca, hoje, um problema de governação do território à escala de aglomeração. Esta condição de "ilimitação" urbana coloca questões sobre os projetos que tendem a restabelecer as relações entre cidade e natureza. Por exemplo, hoje faz sentido pensar, como se tem discutido, os projetos de revitalização como construção de um limite definido entre a cidade e o campo? Tais intervenções não são pensadas como projetos no limite, colocados nos interstícios da cidade ilimitada, onde também os campos, nos seus modos de uso, se tornaram urbanos? Neste sentido, uma reserva natural ou florestal, ou a presença de um curso de água podem assumir um duplo valor, enquanto bens naturais a tutelar mas também enquanto pontos de partida para a construção de uma nova rede de espaços naturais e para o usufruto público.

O valor que exprime o conceito de património é algo que vai para além da propriedade de uma pessoa ou de um país; deve ser de todos. Neste sentido, o património cultural é mundial e cada país tem o dever de o proteger através de um aparato jurídico e dos serviços administrativos e técnicos, de modo a gerir e aplicar as leis do setor. O art. 9 da Constituição italiana lembra que entre os princípios fundamentais de desenvolvimento do país está a cultura, a investigação científica e técnica e a tutela e salvaguarda do património histórico. O processo de desprivatização dos bens patrimoniais começou com o lluminismo e a Revolução Francesa. Formaram-se os grandes museus públicos, as grandes propriedades aristocráticas tornaram-se domínio público, com os seus grandes parques, que em muitas cidades se tornaram os principais jardins públicos.

Mas, nas últimas décadas, assistimos cada vez mais ao emergir de posições contrastantes. Se por um lado uma parte da sociedade está mais convicta do direito da sociedade a fruir dos bens culturais, por outro há uma componente social orientada para a privatização. As razões que tornam o património cultural em bem coletivo são por demais evidentes. Trata-se de bens que exprimem a história e as identidades de um país, são manifestações do engenho e da cultura expressa por um povo ou comunidade e representação de um património insubstituível para o enriquecimento cultural e a educação da coletividade. Se esta consciência estava antes associada apenas aos bens artísticos e monumentais, hoje inclui também o ambiente, o tecido urbano histórico, a paisagem e, portanto, tem influência em todos os processos de transformação urbana e territorial. 
Na ideia de património prevalece, por fim, o seu valor universal ou o facto de ser fonte e alimento das identidades locais? O tema é controverso, hoje vivemos numa sociedade globalizada na qual, para ser ator do próprio desenvolvimento, uma comunidade deve ter consciência da importância da sua própria identidade, na qual se inclui também o cruzamento extraordinário entre a história e as construções e lugares que constituem o património.

Mas esta consciência alerta-nos para as nossas responsabilidades: a sua conservação para proveito de toda a humanidade; a sua valorização, evitando identificações folclóricas ridículas e, por fim, a capacidade de governar e de gerir as transformações e as modificações dos contextos urbanos, territoriais e paisagísticos em que se encontram os bens patrimoniais. Se nem tudo pode ser património, é igualmente importante ter a consciência de que não devem existir territórios e paisagens sem qualidade. Uma qualidade a encontrar até nos elementos mínimos que compõem a estrutura de um território ou cidade, como o desenho de uma estrada ou uma boa organização dos espaços de convívio. Também a qualidade dos espaços de vida quotidiana podem, a este respeito, representar um fator de identificação local importante para o desenvolvimento de um território inserido em dinâmicas globais.

\section{Cursos de água e cidades: um património de projeto}

O tema condutor deste projeto teve em conta uma reflexão comparativa sobre o papel cultural e estrutural dos cursos de água nas estratégias e nos processos de regeneração urbana. A importância da água na configuração dos espaços urbanos é um tema que foi várias vezes objeto de estudo, de reflexões e projetos, assim como o estudo dos processos de transformação que sancionaram a sua modificação em espaços muitas vezes utilitários, simbólicos ou monumentais.

Por todo o mundo, grande parte das aglomerações urbanas cresceram ao longo ou em redor das bacias de água. Os rios, as lagoas, os deltas, os estuários e, por fim, as costas representaram o suporte geomorfológico que favoreceu a fundação e o desenvolvimento de muitas cidades. A sua localização precisa e a variedade das suas formas foram certamente condicionadas por configurações do solo para permitir espaços mais facilmente urbanizáveis, como ficou evidente em numerosos estudos de geografia (Gourou, 1973; Ortolani, 1984). De resto, como nos demonstram as civilizações potamitas, a evolução das cidades da Antiguidade e Idade Média não seria sequer concebível sem uma relação direta com um recurso fundamental desta natureza. Nos processos de aglomeração urbana, a água teve um papel fundamental na escolha da localização da cidade, assim como no desenvolvimento de culturas urbanas fortemente influenciadas pela presença da água; essencial também para o reforço do desempenho económico estratégico de uma aglomeração, com vista ao desenvolvimento de atividades comerciais e industriais e de infra-estruturas estratégicas como os portos e as auto-estradas.

Quando contemplamos cidades que cresceram sobre a água, saltam à vista as formas mais visíveis da interação entre o espaço urbano e o da água, como uma riviera ou um paredão; frequentemente admiramo-nos com a separação entre o rio e a cidade devido à construção de uma infra-estrutura. 
A relação é, na realidade, muito mais complexa. Esta é visível nas transformações da morfologia que deixaram rastos visíveis na estrutura da cidade, como uma estrada sinuosa, um tecido urbano ortogonal, ou ainda na toponomástica. Noutros casos, a água foi simplesmente ocultada e conduzida para o subsolo, como nos canais de Bolonha ou de Paris. Na antiguidade, a relação com a água era dúplice. O rio era um recurso no sentido amplo que permitia o funcionamento das cidades e o desenvolvimento da agricultura. Mas assumia também um valor simbólico e religioso, conferindo significados culturais a determinados lugares ou associando fenómenos inexplicáveis a divindades.

As problemáticas colocadas pelas cidades de água e, mais em geral, das paisagens urbanas fluviais, constituem também uma ocasião para refletir sobre as complexas relações entre cidade e hidrografia e sobre os efeitos da presença de um curso de água nos processos históricos de organização urbana, ou ainda sobre como as dinâmicas de urbanização, nesta época moderna e contemporânea, apagaram, redimensionaram e alteraram esta presença "natural" (Ercolini, 2010). A relação entre cidade e rio na história não é por certo unívoca, pois as condições geográficas e culturais e os diferentes processos históricos determinaram numerosas variantes e o desenvolvimento de casos específicos. A construção de uma cidade ao longo de um rio representa o êxito de um processo de interpretação das condições geográficas e geomorfológicas de um sítio que associa diversas exigências: uma relativa segurança hidráulica, boas condições de defesa, uma acessibilidade controlada, e a possibilidade de usar a água como recurso energético. Nas épocas posteriores à Revolução Industrial, o maior conhecimento técnico adquirido começou a tornar os modelos de aglomeração mais independentes do contexto físico-geográfico. A relação de subsistência diminuiu, muitas vezes desapareceu e as cidades começaram a domesticar o rio e a adaptá-lo a novas lógicas de funcionamento. O rio torna-se, portanto, uma área industrial, auto-estrada, infra-estrutura, área de tratamento ou descarga.

Mas o conhecimento hidráulico é um savoir faire que está intimamente ligado à evolução dos modelos e das técnicas de construção dos espaços urbanizados. O aperfeiçoamento das técnicas de infra-estruturas territoriais e urbanas e do controlo hidráulico por parte das civilizações, que foi sendo redimensionado ao longo do tempo, permitiu a construção de lugares que se tornaram monumentos ao engenho humano e, enquanto memórias, em alguns casos foram inseridos pela UNESCO na lista do património mundial da humanidade. Na Mesopotânia, diversos canais ligavam o Tigre e o Eufrates, que eram utilizados também como vias de navegação, e os imperadores persas, determinados em conquistar o Egipto, levantaram o problema da ligação entre o Nilo e o Mar Vermelho. Mas o conhecimento hidráulico não era apanágio apenas das culturas desenvolvidas à volta da bacia do Mediterrâneo ou do Médio Oriente.

No Vietname, a antiga capital Huê, declarada nos anos 1990 património mundial da humanidade, é um exemplo de uma cidade situada entre a montanha e o rio Houng, que correspondia em pleno aos princípios de aglomeração de Feng Shui. O aspeto que emerge da leitura da estrutura urbana histórica, fundada na articulação de um conjunto de locais, é o de um conhecimento extraordinário em definir o papel da água na organização urbana. A água desenvolve uma pluralidade de funções que vai da defesa, acessibilidade, irrigação, ao controlo do risco hidráulico. Huê foi uma cidade fundada no final 
do século XVII, portanto relativamente recente, mas o seu conhecimento hidráulico nasce do rico património de saberes consolidado na península indo-chinesa, com a experiência da cidade de Angkor. A capital do império, Kmer, constituía um extraordinário exemplo de planificação de um território através da predisposição de um sistema artificial de canais e bacias de água, necessários à vida urbana e ao cultivo agrícola, valendo-lhe a denominação de cidade hidráulica (Grosiler, 1979; de Bernon, 1997).

Na China, desde o terceiro século antes de Cristo, procedeu-se à construção de canais que desenvolviam a dupla função de irrigar os campos e consentir o movimento de mercadorias e pessoas. A construção do "grande canal" da China, iniciada no século $\vee$ d.C. representou uma extraordinária obra porque introduziu princípios de engenharia hidráulica depois desenvolvidos também na construção de navios europeus. O "grande canal" liga uma série de cidades de água, hoje com populações entre os 4 e os 6 milhões, de grande importância quer para a estrutura urbana histórica, crescida em simbiose com a tal rede de canais e de lagos, quer para a radicalidade dos processos de transformação urbana, em curso há algumas décadas e que levaram ao desaparecimento desse património. Entre estas cidades encontramos Hangzhou, Suzhou e Wuxi. O forte processo de crescimento demográfico e industrial por que passaram levaram a uma transformação, por vezes radical, dos espaços fluviais, sem, no entanto, apagar a sua importância e função na estrutura urbana e nas culturas locais (Xiaocong e Lamouroux 1995; Scherrer 2004).

As transformações urbanas que proporcionaram o contacto entre as cidades e os cursos de água foram marcadas por diversos ciclos económicos que condicionaram o desenvolvimento urbano e por processos de modernização sucessivos. Basta comparar as cartografias históricas de uma cidade para nos apercebermos da razão de tais transformações. Em alguns casos, o espaço fortificado das cidades medievais define uma separação nítida entre o espaço da cidade e o da água, ainda que este último seja um pulular de atividades ligadas à economia citadina. A integração entre as atividades que se desenvolvem ao longo da costa e os espaços da cidade é mais intensa quando uma cidade é atravessada por um rio. As representações de Paris, anteriores às transformações das margens do Sena num sistema de paredões, mostram-nos um frenesim ligado às várias atividades portuárias, segundo uma lógica de especialização, ao longo de todo o curso urbano do rio. Demonstra também a variedade de usos do rio, com as estações de bombagem de água como La Samaritaine, com moinhos que usavam a corrente do rio como força necessária para o seu funcionamento, com as águas que eram utilizadas como descarga para os trabalhos nos bairros artesanais erigidos ao longo do rio. A partir do século $\mathrm{XVI}$, este espaço começou a ser "artificializado" com a construção de cais em pedra, começando assim o processo de transformação urbana e monumental do troço urbano do rio que levou, em 1991, a UNESCO a considerar as margens do rio Sena património da humanidade. Paris representa neste aspeto um estudo de caso de grande interesse, na relação rica e controversa que a cidade estabeleceu com o seu rio. O século XVIII foi um século de relevantes projetos e transformações no que diz respeito aos espaços do rio. Algumas intervenções mudaram decisivamente a fisionomia desta parte da cidade, como no caso da demolição das pontes habitadas, iniciada na segunda metade do século XVIII. A importância "monumental" do rio é claramente evidenciada em numerosos projetos de 
embelezamento, com as vicissitudes do plano fantástico elaborado por Pierre Patte, após o concurso para a realização da praça dedicada a Louis XV, a chamada Place de la Concorde. Mas durante vários séculos as atividades fluviais foram verdadeiramente intensas e os vários portos eram subdivididos por categorias de mercadorias. No início do século XIX, Napoleão retomou os trabalhos no rio Sena dentro de uma estratégia para a capital e a renovação monumental ligou-se à adequação das infra-estruturas e ao saneamento higiénico. Os portos foram reorganizados e foram interditas todas as atividades de mercado que se desenvolviam quotidianamente à sua volta; o rio foi assim concebido como uma infra-estrutura de mobilidade e, sobretudo, torna-se objeto de decoração urbano (Le Moël, 1997; Lalandre, 2004).

É necessário esperar até aos séculos XVII e XVIII para que os rios comecem a assumir um papel importante na beleza urbana. Podemos referir cidades como Nantes, Bordéus, Coblença, Salzburgo e, por certo, Dresden: uma das cidades que melhor soube modelar-se à volta do rio, transformando-o num espaço cénico, como lembra Bernardo Bellotto. O século XVIII é o século dos grandes desafios da cultura iluminista. Paris, Londres e Amesterdão eram as capitais do desenvolvimento da ciência e da técnica e esta tensão de afirmação do conhecimento influenciou também os protagonistas das monarquias absolutas (Rossi Pinelli, 2009). Esta tensão manifestou-se também na vontade de submeter um contexto natural extremo à vontade política de um soberano e à supremacia da técnica. A esse propósito, a experiência mais relevante na Europa nessa época foi certamente a construção da nova capital russa de São Petersburgo por parte de Pedro o Grande, no delta do rio Neva. As vicissitudes desta cidade, assim como os numerosos projetos que estudaram a sua forma, foram objeto de várias reconstruções históricas, sobre as quais não nos iremos alongar (Lo Gatto, 1991; Antsiferov, 2003; Corboz, 2003); referimos apenas o seu carácter internacional evidenciado por Francesco Algarotti, que nas suas cartas escritas na primeira metade do século XVIII referiu o espetáculo grandioso de uma cidade - janela da Europa - na qual se cruzavam influências estilísticas italianas, francesas e holandesas.

Outro aspeto a destacar sobre a patrimonialização e valorização dos cursos de água é a rede de canais que sulcam o território de muitos países europeus. Os canais são um extraordinário exemplo de consolidação, ao longo do tempo, de um conjunto de estruturas urbanas, espaços de infra-estruturas, espaços públicos e fortificações, o que os torna hoje uma das forças das estratégias de valorização cultural e turística dos territórios atravessados por estas vias de água. A este respeito, a França é certamente um dos países mais ativos. Grande parte dos portos franceses foi construída nos rios e o grande desenvolvimento da atividade portuária, que se deu com o reforço do colonialismo, trouxe entre o século XVII e XVIII uma transformação de numerosas cidades fluviais próximas do mar, como por exemplo, Bordéus e Nantes na costa atlântica.

Se inicialmente a navegação fluvial francesa se interessou pelos cursos de água, tornando-os navegáveis (Sena, Mosella, Reno, Ródano, Garona, Loire, etc.), entre o século XVII e XVIII, procedeu-se à construção de uma rede de canais para a ligação de várias cidades do país. As razões económicas desta vasta operação de infra-estruturas são evidentes (trata-se de fazer circular mercadorias). Mas estas entraram em crise quando a concorrência da ferrovia e a função de infra-estrutura dos canais 
diminuiu progressivamente. Foi necessário esperar até à segunda metade do século XX para verificar o relançamento dos canais e a sua valorização enquanto património histórico e infra-estrutura cultural (Farinella, 2005). Segundo o historiador francês Pierre Pinon (2005), estamos perante um desenho utópico iniciado no século XVII, sonhado no século seguinte e realizado apenas parcialmente no século XIX. Mas ainda que parcialmente, no período de três séculos, o território francês foi dotado com cerca de 16.000 quilómetros de canais que hoje constituem um importante património histórico, paisagístico e turístico.

Na Europa, a construção dos canais acompanhou, inicialmente, mais do que as estradas, a infra-estruturação do continente. Os historiadores da paisagem medieval (Le Goff, 1981; Fumagalli 1988) disponibilizaram-nos eficazes descrições da reconstruída rede urbana europeia. Assim como as imensas florestas, os grandes rios marcavam a geografia do continente, enquanto as terras eram muitas vezes mais ricas em água do que em solo. A conquista de terrenos cultiváveis tornou-se subitamente um desafio ligado às urgentes exigências do solo, que se começaram a manifestar após os processos de crescimento da população e a consequente "fome de terra" que percorreu a Europa no final da Idade Média.

Giovanni Botero, em 1588, descreveu fielmente o processo de "colonização" do território europeu. No seu texto As causas da grandeza das cidades, descreveu os territórios da Flandres e da Lombardia atravessados por canais e embarcações que permitiam, desde a Idade Média, o deslocamento de mercadorias e pessoas. Trata-se de canais "feitos com arte" que representavam um eficaz sistema infra-estrutural para o transporte das mercadorias para ligar, no caso de Milão, a cidade com os lagos e os principais rios do território. A construção e adequação destas redes continuaram durante o século XVIII e influenciaram profundamente a morfologia e organização de muitas cidades, em particular na Lombardia, Emília Romana e Veneto (Cattaneo, 1999; Mioni 1976). Hoje, este sistema infra-estrutural perdeu a sua função original mas adquiriu um valor patrimonial.

São vários os aspetos que conferem valor patrimonial a um canal. Em linhas gerais, esse valor deve-se, por um lado, à qualidade intrínseca do canal como obra artesanal e, por outro, à sua valência territorial. Mais precisamente, um canal é um conjunto de obras de engenharia hidráulica que permite superar os obstáculos naturais, enquanto o seu caráter paisagístico está presente na sucessão de eclusas, casas de guardas, cais, contra-canais e plantações que definem a sua peculiaridade como objeto ou estrutura paisagística. Por fim, podemos mencionar a sua conotação urbana com uma incidência na forma, que muda de acordo com a consistência da cidade atravessada. Isto verifica-se na estrutura minimal de um cais numa pequena vila, ou na configuração, nas grandes cidades, de setores urbanos inteiros, marcados também pela atividade portuária (Farinella, 2008).

O retorno da navegação fluvial nos grandes rios, originado pelo aumento das dimensões das embarcações de transporte de mercadorias, determinou a perda de importância da rede de canais e deixou no território um património de vias de água que se tornaram, ao longo do século XX, uma importante força turística. O turismo fluvial em França foi redescoberto no início dos anos 1960 e, num espaço de três décadas, tornou-se um fenómeno que envolveu mais de 10 milhões de pessoas (Damien, 2001).

Para numerosos territórios rurais, a presença de um canal histórico significou o lançamento de projetos ligados à valorização de "identidades" territoriais fundadas na associação de diversos fatores: 
cursos de água, paisagens vinícolas, cultura gastronómica, e a presença variada de bens arquitetónicos e paisagísticos no território europeu.

Mas no decurso do século XX, as transformações operadas nos contextos fluviais comprometeram muitas vezes a riqueza ambiental, paisagística e urbana dos cursos de água. Para além do valor patrimonial e ambiental, estes possuem potencialidades ecológicas, paisagísticas e urbanas que os tornam, se devidamente reestruturados, em estruturas privilegiadas para devolver forma e significado a mais vastos sistemas de espaços abertos (urbanos, rurais, naturais) necessários para contrastar e reequilibrar o crescimento urbano e para requalificar o território. A experiência, iniciada no início dos anos 1960 na bacia industrial e mineira de Ruhr demonstra-nos como se pode transformar um território inutilizado numa paisagem cultural. É necessário agir de forma integrada na reabilitação ambiental, na recuperação paisagística e na requalificação urbana e, de resto, diversas operações iniciadas em várias cidades europeias mostram-nos os processos de regeneração dos espaços de água, sobre os quais falaremos na secção seguinte.

\section{Cursos de água e estratégias de requalificação urbana}

O debate sobre o início das cidades na Europa e nos países ocidentais gira em torno de alguns temas gerais que dizem respeito, antes de mais, à reconversão das políticas urbanas e territoriais para um desenvolvimento sustentável, de modo a transformar as cidades em ecossistemas urbanos, em lugares de biodiversidade, em paisagens culturais cada vez mais complexas.

Isto significa pensar, antes de mais, na dimensão e nos limites das cidades contemporâneas. O tema da difusão urbana (Indovina et al., 1990) está no centro das nossas reflexões desde há trinta anos para cá; no final do século passado, começou a utilizar-se o conceito de requalificação urbana (depois chamada regeneração) para reativar áreas abandonadas por atividades industriais que fecharam ou que foram deslocalizadas, ou que continham infra-estruturas viárias ou ferroviárias inutilizadas ou de excessiva dimensão. As causas do impacto da dispersão urbana no território em termos de consumo de solo agrícola foram evidenciadas, por diversas vezes, em estudos e pesquisas no território italiano e europeu (Bonora, 2013).

As políticas e as ações para a regeneração dos espaços urbanos não impediram, contudo, a progressão da urbanização do solo europeu e, de um modo particular, do italiano. É de sublinhar a importância estratégica e estrutural seguida por numerosos projetos de requalificação urbana para relançar as cidades europeias e as suas atividades económicas e sociais, em particular após a crise industrial do fim do século XX. No que respeita à cidade de água, a redefinição e extensão do conceito de espaço público e a regeneração das antigas áreas portuárias históricas, marcaram a experiência de numerosas cidades portuárias, entre as quais Lion, Bordéus, Hamburgo ou Génova.

Uma série de temas estruturais que emerge cada vez mais dos debates sobre as nossas cidades diz respeito à relação entre cidade e natureza, ou é sintetizada pela expressão "qualidade urbana". 
Mas a procura de qualidade, quando se trata dos espaços da cidade, pode assumir vários modos. Há que ter em conta as características de desempenho dos edifícios e os padrões ligados ao desempenho energético que, também por implicações diretas com o mercado da construção civil, são frequentemente enfatizadas nos debates sobre o futuro dos nossos ambientes de vida. Talvez não faça muito sentido pensar em edifícios ecologicamente sustentáveis no que diz respeito ao ciclo da água, à poupança energética ou à utilização de painéis fotovoltaicos se depois colocamos estes edifícios na lezíria de um rio ou os usamos como pretexto para a urbanização de espaços extremos como um deserto, ou para a construção de ilhas urbanas "ecologicamente sustentáveis" junto ao mar, em costas já densamente urbanizadas. A sustentabilidade é um conceito complexo e requer a integração e sinergia entre todos os componentes que estão na base do processo de construção. Falamos da cidade, com a sua estrutura de relações sociais, culturais e económicas, a sua geomorfologia, a sua história e, portanto, de um conceito que rejeita as simplificações que frequentemente reencontramos em muitas sugestões arquitetónicas divulgadas pelos meios de comunicação.

A reflexão teórico-prática respeitante às relações entre cidade e natureza, com todas as implicações problemáticas na organização e na forma da cidade, está em cada caso ligada às escolhas que várias comunidades farão respeitando acordos e protocolos internacionais relacionados com as alterações climatéricas (Kyoto), a transformação sustentável das cidades europeias (Leipzig) ou ainda a Convenção europeia sobre a paisagem, da qual falamos anteriormente. A necessidade de repensar os modelos direcionados para o crescimento urbano apareceu com mais evidência durante os anos 1980 nos países ocidentais industrializados. Nestes últimos trinta anos assistimos à crise do sistema de produção industrial herdado da revolução industrial que fez emergir um vasto património de áreas abandonadas (industriais, infra-estruturais, militares). A reconversão do aparato industrial gerou conflitos sociais relevantes e as cidades tiveram de reinventar uma base económica e um papel no mercado cada vez mais competitivo, no qual essas mesmas cidades se tornaram protagonistas de uma corrida competitiva, local e internacional, para adquirirem funções cada vez mais importantes e exclusivas. Em Itália podemos citar cidades como Génova e Turim.

Um elemento importante de tais estratégias encontra-se na redescoberta da própria identidade histórica associada frequentemente à necessidade de regenerar a enorme quantidade de locais degradados, por vezes históricos, noutros casos bem localizados no interior da cidade ou em pontos de charneira entre o centro histórico e a periferia. Esta reflexão está associada a projetos concretos que se tornaram símbolos da capacidade de governação. Hoje, apesar da crise que aflige as nossas sociedades, assistimos a uma grande atividade por parte dos governantes empenhados em importantes trabalhos de requalificação urbana, que podemos atribuir aos seguintes fatores (Portas, 1998):

1. O início de estratégias importantes e ambiciosas por parte das coletividades locais, como no caso de cidades como Lion, Hamburgo ou de regiões como Ruhr;

2. O aproveitamento de oportunidades geradas por grandes eventos como as olimpíadas ou uma exposição universal que tragam à cidade recursos importantes. Em alguns casos, os processos 
decorrentes destes eventos proporcionarão efeitos positivos na cidade também após o fim do evento (Barcelona, Turim). Noutros casos, os efeitos da requalificação da cidade são mais modestos, senão mesmo negativos, como é o caso de Sevilha;

3. Situações de catástrofe também podem gerar a requalificação da cidade, como é o caso do incêndio do Chiado em Lisboa, mas podem também provocar imobilismo ou dar lugar a processos de reconstrução desadequados, como por exemplo no terramoto de Aquila;

4. Por fim, podemos mencionar os grandes projetos imobiliários, os investimentos dos grandes grupos industriais ou das sociedades que gerem as redes de infra-estruturas. As docas londrinas, as áreas Pirelli, em Milão, ou a recuperação das áreas ferroviárias de Paris Rive-Gauche representam algumas destas intervenções que produziram êxitos por vezes contrastantes entre si.

Os cursos de água foram um dos elementos fundamentais desta longa época de requalificação urbana. Muitas vezes, o próprio nome (Emscher) ou uma particular configuração geomorfológica ou funcional (confluência, margens, portos) identificaram, também mediaticamente, o processo de transformação. Em alguns casos, estes permitiram a reorganização de áreas metropolitanas, contribuindo para a criação de redes de espaços naturais e públicos, transformando-se também em corredores ecológicos. Noutros casos, as estratégias e os projetos concentraram-se em zonas urbanas limitadas, como por exemplo uma área portuária ou uma zona industrial abandonada. Por isso, estas experiências de requalificação urbana referentes à relação entre os cursos de água e as cidades mostram-nos uma rica variedade de intervenções e de ações que oscilam entre a requalificação de um setor urbano e a construção de uma rede de corredores ecológicos ou paisagísticos: duas dimensões que podem, obviamente, coexistir. Não é fácil classificar os diferentes projetos que nas últimas décadas se dedicaram à relação entre a cidade e o rio; a causa é determinada por complexidades de situações históricas, naturais e urbanas, que estão na base destas operações. Além disso, um projeto pode muitas vezes ser avaliado sob uma multiplicidade de fatores que tornam difícil a sua classificação. Todavia, é possível encontrar semelhanças. Um primeiro grupo de experiências diz respeito às cidades que consideraram o rio como espaço público "histórico-patrimonial" a valorizar. As experiências conduzidas em Paris, Lion ou Bordéus são, neste aspeto, emblemáticas. Outras cidades como Varsóvia, Mónaco ou Leicester enfrentaram o problema da requalificação das próprias áreas urbanas através de ações para reforçar o rio como corredor natural ou como espaço a revitalizar. Um terceiro caso pode ser associado à experiência de bairros como Wasserstadt, Berlim, ou Hammerby Sjostad, Estocolmo, que utilizaram uma bacia de água no interior da área metropolitana para receber expansões urbanas de alta qualidade ambiental. Por fim, devemos assinalar o caso mais frequente de recuperação das áreas portuárias. Todas as grandes cidades fluviais europeias, de Londres a Hamburgo, de Bilbau a Nantes, defrontaram-se com problemáticas deste tipo.

Ainda no âmbito dos processos de infra-estruturação de um território, podemos referir também o exemplo da valorização dos canais históricos. Também aqui, as operações desta natureza pretendem 
relançar um determinado território ou cidade dando importância a elementos historicamente relevantes mas esquecidos, e em muitos casos não incluídos nos processos de modernização urbana e territorial do segundo pós-guerra. As experiências a referir são várias, como é o caso das embarcações lombardas e milanesas, a reabertura das embarcações de Bolonha, os territórios da antiga Flandres, como a cidade de Bruges, ou ainda os projetos a decorrerem em Lille e a experiência de Birmingham.

A França, pela extensão da sua rede para a qualidade da paisagem dos canais, representa um caso extraordinário de valorização territorial que associou qualidade da paisagem, fruição quotidiana e local destes espaços, e promoção turística ligada também à sua tradição histórica, gastronómica e vinícola. Uma situação diferente, mas igualmente emblemática, que demonstra as potencialidades que podem derivar da associação entre políticas de paisagem e processos de requalificação urbana é verificável na Alemanha. Trata-se do Ruhr, um território à procura de identidade que referimos anteriormente. É uma antiga bacia mineira rica em carvão e ferro que no início do século XIX passou por um intenso processo de industrialização caracterizado pela construção de ferrovias, estradas e, sobretudo, canais. A reestruturação industrial, iniciada a partir dos anos 1960, e a sua valorização paisagística iniciada vinte anos depois, transformaram esse território numa das paisagens culturais mais dinâmicas em termos de reinvenção e de requalificação urbana e paisagística mas também de governação, como testemunha a experiência de Emscher Park.

Referimos experiências que demonstram que a reabilitação das cidades e das paisagens precisa de uma visão integrada dos problemas e das relações entre a cidade, a paisagem, a natureza, a cultura e a economia. A ecologia urbana, a este propósito, é importante. A noção de ecossistema está intimamente associada às interações que se libertam entre os seus elementos estruturais. Dependem principalmente das relações que se estabelecem entre a parte e o todo, como salienta Edgar Morin (1992) e é na qualidade destas relações que reencontramos a complexidade e a organização de um sistema. Se um curso de água pode ser associado a um ecossistema composto por espaços urbanos rurais e naturais, estes devem tornar-se elementos interdependentes, ainda que dotados de uma própria especificidade.

O desafio do projeto contemporâneo é pensar e gerir a complexidade e as ações, possíveis e necessárias, que devem ser compatíveis com a sustentabilidade e com uma abordagem multidisciplinar. Questões como a qualidade da água, as relações com a cidade existente, as identidades históricas e a heterogeneidade devem ser associadas a estratégias de médio e longo prazo, em que se proceda à condução de ações de projeto fundadas numa renovada e mais avançada parceria entre o público e o privado, e que incluam o envolvimento real e participativo das comunidades locais. Sob este ponto de vista, a União Europeia, com os programas de intercâmbio, ajuda, cooperação e solidariedade representa uma oportunidade de troca e partilha de experiências. A regeneração dos espaços urbanos requer um trabalho constante fundado na junção de diversas competências profissionais e no contacto constante com os diversos interessados. Hoje, fazer parte de uma rede que partilha problemáticas, temas e experiências constitui uma oportunidade importante para qualquer cidade, pois é possível encontrar soluções adaptáveis às necessidades específicas. 


\section{Referências bibliográficas}

Antsiferov, N. P. (2003), L'Ame de Saint-Pétersbourg. Paris, B. Giovanangeli.

Bandarin, F. e van Oers, R. (2012), The Historic Urban Landscape: Managing Heritage in an Urban Century. Chichester, JOHN WILEY \& SONS INC.

Berque, A. (1995), Les raisons du paysage. De la Chine antique aux environnements de synthèse. Paris, Hazan.

Bonora, P. (Orgs.) (2013), Atlante del consumo di suolo. Per un progetto di città metropolitana. Bolonha, Baskerville.

Cattaneo, R. (1999), Metodo e strumenti della nuova programmazione regionale. Roma, Laterza.

Chastel, A. (2012), Architecture \& patrimone. Paris, Éditions du Patrimoine.

ChoAy, F. (1993), L'Allégorie du patrimoine. PARIS, Le Seuil.

ChoAy, F. (2011), LA TERRE QUI MEURT. PARIS FAYARD.

Corboz, A. (2003), Deux Capitales françaises. Saint-Pétersbourg et Washington. Paris, Infolio éditions.

Damien, M. M. (2001), Le tourisme fluvial. PARIS, PUF - Que SAIS-JE?

de Bernon, O. (1997), Note sur l'hydraulique théocratique AngKorienne. Bulletin de l'ECole FrançaISE D'EXTRÊME, 84, P. $340-348$.

Ercolini, M. (2010), Cultura dell'acqua e progettazione paesaggistica. Roma, Gangemi.

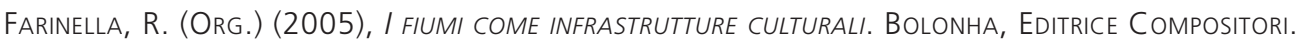

Farinella, R. e Ronconi, M. (Orgs.) (2008), Territorio, fiumi, Città. Esperienze di riqualificazione in Italia. Sant'Arcangelo DI ROMAgna, MaggiOLI.

Fumagalli, V. (1988), La pietra viva. Città e natura nel Medioevo. Bolonha, il Mulino.

Gambino, R. (1997), Conservare Innovare. Paesaggio, Ambiente, Territorio. Torino, Utet.

Gourou, P. (1973), Pour une géographie humaine. Paris, Flammarion.

Groslier, B. P. (1979), LA CITÉ hydRAULIQUe ANGKORIENNE: EXPLOITATION OU SUREXPLOITATION DU SOL ? BULLETIN DE L'ECOLE FRANÇAISE D'EXTRÊME-ORIENT, 66(1), P. 161-202.

INDOVINA, F. ET AL. (1990), LA CITTÀ DIFFUSA. VENEZA, DAEST-IUAV.

Lalandre, A. (2004), Histoire des ports de Paris et de l'lle de France. Rennes, Éditions Ouest-France.

LE GofF, J. (1981), LA CIVILTÀ DELL'OCCIDENTE MEDIEVAlE. TURIM, EINAUdi.

Le Moël, M. (1997), L'urbanisme parisien au sièCle des Lumières. PARIS, Action Artistique de la Ville de Paris.

lo Gatto, E. (1991), Il mito di Pietroburgo. Milão, Feltrinelli.

Magnaghi, A. (2010), Il progetto locale. Turim, Bollati Boringhieri.

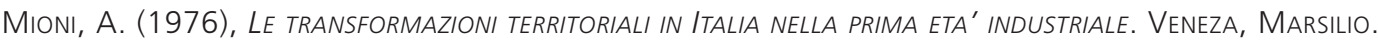

Morin, E. (1992), Il metodo. Ordine, disordine, organizzazione. Milão, Feltrinelli.

Ortolani, M. (1984), Geografia delle Sedı. PÁdova, Piccin.

Pinon, P. (2005), Patrimoine fluvial. Canaux et Rivières navigables. Paris, Nouvelles éditions Scala.

Portas, N. (1998), L'emergenza del progetto urbano. Urbanística, N.110, pp. 51-60.

Rossi Pinelli, O. (2009), Le arti nel Settecento europeo. Turim, EINAudi.

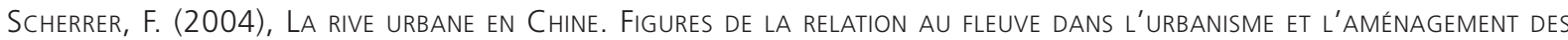
Villes du bas Yangzi. GÉocarrefour [Le Yangzi et le RhÔne, Regard Croisés]. Lyon, 79(1), 41-48.

Settis, S. (2010), Paesaggio Costituzione Cemento. Turim, Einaudi.

Xiaocong, L. e Lamouroux, C. (1995), La formation de réseaux urbains dans la Chine du XIE SIĖCLE. BULletin DE L'ECOLE FRANÇAISE D'EXTREME-ORIENT, 82(1), P. 185 - 199

Toppetti, F. (Org.) (2012), Paesaggi e città storica. TeOrie e politiche del progetto. Florença, Alinea. 